\title{
Evaluating of Noise Pollution in the Airside of Imam Khomeini International Airport
}

\author{
Shabani, Sh. ${ }^{1} \&$ Zarei. Sh. ${ }^{2}$ \\ ${ }^{1}$ Assistant Professor, Dept. of Civil Engineering-Road \& Transportation, North Tehran Center, Payame Noor \\ Univ. (PNU), Tehran \\ ${ }^{2}$ MSc student, Dept. of Civil Engineering-Road \& Transportation, North Tehran Center, Payame Noor Univ. \\ (PNU), Tehran \\ Correspondence: Zarei. Sh., Dept. of Civil Engineering-Road \& Transportation, North Tehran Center, Payame \\ Noor Univ. (PNU), Tehran. E-mail: zarei_shahrokh110@yahoo.com, shabani@iust.ac.ir
}

Received: November 23, 2016

Accepted: December 23, 2016 Online Published: April 23, 2017

doi:10.5539/mas.v11n6p47

URL: https://doi.org/10.5539/mas.v11n6p47

\begin{abstract}
Detection, measurement and monitoring of environmental pollution are considered as one of the decision basics in the environmental management. Principle planning for solving environmental problems is not possible without reliance to assured measurement with the help of new and powerful systems in monitoring. In this regard the noise pollution of airports is of great importance. In this paper by using device analysis method and utilizing a calibrated sound level meter device, sources of noise pollution recognition, noise and sound pressure level measurement, evaluation and comparison of them with environmental standards, and airside control actions of the Imam Khomeini international airport have been performed and it was showed, that the runway, ground safety and the dock have been respectively the main pollutants, so that noise pollution in the Apron area and runway at night have been $80.7 \%$ more than Iran standards and the ground safety site while alarm broadcasting has been $53.1 \%$ at daytime and $61.1 \%$ at night more than standards and these values for Dock has been $20.88 \%$ and also the value of noise pollutants in water refinery sites, watchtower, taxi parking and pilgrim terminals have met standards. Finally some solutions against noise pollution have been proposed.
\end{abstract}

Keywords: noise pollutant, airport, environmental

\section{Introduction}

Environment is a combination of different knowledge in science, which include a collection of biological and environmental agents in the form of biological or abiotic (physical or chemical) that affects and is affected by the life of an individual or species. Nowadays, this definition is mainly related to humans and his activities and the environment can be summarized as a collection of natural factors of the earth planet which surrounds the human (Ravanshadnia, 2014). The difference of environment with the nature is that the environment includes the collection of natural, biological and abiotic factorsthat are considered exclusively, while, the environment is characterized from the human view and based on the interaction between human and nature. In comparison to many environmental problems, noise pollution is continuously growing and like other type of the environment pollution has direct and indirect effects on the health of human. Although, this type of pollution has not yet found its place and it is not spoken much about its effects, but it has stimulated the compliant of many people. From the consequences of it sleep disorder, annoyance for different groups, physical disorder, Heart disease, high blood pressure, stress, mental disorders, speech disorders, vestibular function, balance system, artery disease, dysregulation of the body's metabolism, headaches, fatigue, excitability, irritability and dyspepsia and be numbered. Noise pollution is a very important factor on the human health which, unfortunatelyless attention has been paid to.

Among noise pollutions, the noise pollution due to airports has a special place. The noise pollution of the aviation system is divided into two category of the noise related to the ground operation and air operation. In the air operation, factors including ramp, noise, creep from the station toward the station point at the creep band, the noise at the starting point of turning, the noise related to the air control, maintenance methods and the selection of the climb power, the noise of flight path in the rural areas, sound barrier which overshadows the grounds near the flight path over the sea, approach maintenance, determining the landing way, final approach and creep to the 
station are the causes of the noises.

In ground operation, factors including engine testing on the ground, the airport traffic noise, ground safety services and the noise of auxiliary power units in the loading portion, fire stations, Marshalr and Shuttle car traffic cause pollution. The ground operations often influences the airport crowd and residents and air operation influence the population, which is located at a farther distance from the airport.

\section{Definition of the Problem and the Goals of the Study}

Based on the international regulation like international civil aviation organization (ICAO), international air transport association (IATA) and federal aviation administration (FAA) the necessity of designing airports as complicated dynamic systems is mentioned which naturally seeks solving problems include noise pollution. Management, monitoring and control of environmental pollutants are among great environmental strategies and are one of the indicators of development of modern societies and without compliance with the principles of sustainable development and environmental protection; it is not possible to imagine a desirable future for the present generation and future generations.

Thus, in this study using analysis method, the identification of the noise pollutant sources, measurement of the noise and equivalent sound level (Leq), its evaluation and comparison with the environmental standard limits and finally performing control actions in the ground part of the International Imam Khomeini airport has been performed by the calibrated sound level meter instrument cell 450 of the Casella British Company and using the standard EPA-40CER-P204.

\section{Background}

In 1990, Huddart with a study he did on the trees of the urban areas concluded that trees can be used for reducing the noise from 5 to $10 \mathrm{~dB}$ in urban areas (Huddart, 1990). In 2005, Chih-Fang Et.al Studied the effect of tree belt in absorption of noise pollution and presented the results in a regression model (Fang \& Ling, 2005). In 2008, Maleki et al studied the importance of urban green space in reducing the noise pollution and showed that afforestation with acacia can be effective in decreasing the noise pollution 8 to $12 \mathrm{~dB}$ (Maleki et al. 2008). In a study by Fan Yang et al in 2011 on the effect of plants beside the streets on decreasing the psychological effects of noise pollution which was conducted using questionnaires, 90 percent of people believed that landscape plants help in reducing the noise pollution (Fan, Yang, 2011). In 2011, Shiraziyan and Frohid investigated the effect of airport noise pollution in the surrounding residential areas and proposed suggestions (Shirazian \& Frohideh, 2011). The studies performed by MahirGokdak in 2012 shows the high level of resentment due to noise pollution in the people between 30 to 49 years old in comparison with the people with the age less than 30 or more than 49 years old (Mahir, 2012). In 2012 Tari et al regarding the desirable level of the activity of the Mehrabad-Airport performed a noise analysis by utilizing of NEF modeling software and limited the traffic level of Mehrabad to 10 million passengers with restriction in night flight (ZabihiTary et al. 2011). In 2013, Yazdi et al performed measuring and monitoring the noise pollution due to Yazd airport and proposed some suggestions (Yazdi et al. 2012). In 2013, Gravi brought up the role of airplane noise pollution on the environment and has propounded the international rules and obligations (Geravi, 2012). In 2013, Khali and Frohid in a study by using Risk priority number (RPN) index have evaluated some factors in the airport, which shows that the effect of noise pollution is more than the other factors (Khali \& Frohideh, 2012). In 2014, Ezati and Atiekakr, propounded a study on the effect of urban noise pollution with emphasis on the effect of traffic pollution on human and in a sampling, mentioned the average weight vehicle as the main pollutant car (Ezati \& Atiekar, 2013). In 2014, Oveisi et al modeled the 20-year proposal of Mehrabad airport noise pollution with the aim of determining its surroundings land use (Naseri, Irani \& Dehkhodarajabi, 2016).

In a study that the effect of airplane noise on the general health of the residents living around the Amsterdam Schimpolhas been investigated, it has been found that between this population and the use of sleeping pills and sedatives and cardiovascular drugs and frequent use of them there is a significant relation (Oveisi et al. 2013). Also studying the residuals of areas around the Kunsan military airport of the Republic of Korea, which were based on their distance divided to three groups and their age was between 30 to 79 years old, it was determined that 45.5 percent of the control group and, 71.8 percent of the group who exposed to low noise and 77.1 percent of the group who exposed to excessive noise were suffering from sleep disorders (Fransses, 2014). Another study about the risk of psychiatric disorders due to airplane noised in the Gillaques region around the Elmas airport (Sardinia, Italy) was showing long-term anxiety among the residents of those areas (Jeony, 2014). Also, based on the studies of professor Stansfald, noise pollution causes sleep disorder, cardiovascular diseases, psychopathy and decrease in hearing of the children (Hardoy, 2005). In 2015, Araghi and Yaghobi studied the effect of noise pollution of the Birjand airport on the residuals around it and in a statistics society presented conclusions about 
the impact of noise pollution in the sleep disorder of the residuals (Stamsfeld, 2003).

Many studies have been performed about noise pollution of the airports,however, no documents is available about the noise pollution and its magnitude in the ground operation part and this kind of noise pollution needs more studies (Araghi \& Yaghobi, 2015; Saffarzadeh \& Rahimi, 2003).

\section{Methodology and Measurement Style}

To evaluate the noise pollution of an environment, it is needed to pass four completely separate phases which are:

1. Recognition of the noise pollution sources

2. Measurement of the noise

3. Evaluation with creditable standards

4. Performing Control actions if the noise is more that the allowed threshold

And also, to control the noise pollution the following three steps should be considered:

1. Reduction and control of noise source

2. Reduction and control of the noise in the direction of noise propagation

3. Reduction and control of the noise in the sound receiving place

In this study subject to the abovementioned items the way of measuring environmental noises of the Imam Khomeini airport with the analysis method utilizingCasella CEL -450 sound level meters produced in England and based on the EPA-40CER-P204 standard and the recipe inserted in the book of environmental standard regulations is mentioned. This device is adjustable for sound in three A-C-Z networks. Measurement in the situations Slow-lmp-Fast, sound analysis at the active band centers and the ability to maintain the results and reread is possible with this device. For measuring the sound based on the intended location the method of environment measuring and evaluation is used. The result of this method is used for determination of the sound pressure level distribution and risk areas and also the determination of the main sources of noises for controlling the noise. The abbreviation of $L_{\mathrm{AS}}$, inthe overall sound level measurement stand for:

L: sound level

A: measurement network

S: microphone response time

Generally three time distribution network is available

FAST: the measurement is done at $125 \mathrm{~ms}$ intervals and this setting value is used most of the time

SLOW: the measurement is done in 1 second

IMPULSE: the measurement is done in $35 \mathrm{~ms}$

Also the measured parameters are as follows:

Leq: Continuous equivalent level,which is the best parameter to obtain the average sound pressure level. When the impulse time distribution is used, this parameter is named Lim

L Max: the maximum sound pressure level at the measured time,

L Min: the minimum sound pressure level at the measured time,

\section{Device specification and method standards}

This device is composed of three main parts including microphone, processor and monitor.

Microphone: Microphone flow based on sound pressure exerted on the diaphragm produces electric corresponding current

Processor: in the processor based on its capabilities and operator's needs, the Information received from the microphone is amplified weighted and processed. Processor device Includes pulse amplifier, reducer, frequency weighting network, network of device response time control and calculation circuits for special applications

Monitor: the processed data inthe processor are digitally sent to the monitor Also, the standards of the device method are based on table 1 . 
Table 1. Device method standards

\begin{tabular}{l}
\hline ANSI IEC-61672 \\
ANSI S1.4 (R1997) \\
IEC 60651(1994) \\
IEC60804(2000) \\
\hline
\end{tabular}

For accuracy in measuring environmental sound, the following considerations have been performed

1. The exact location of measuring station based on sound sources, space, propagation period and sound continuity is selected in the vicinity of the site

2. The station place has been selected in such a way that the resonance or Doppler Effect does not happen.

3. The height of the device placement is selected based on the acoustical barriers.

4. The microphone of the device is located without angle relative to the source

5. To eliminate the air flow over the microphone surface protective foam is used

6. Standing in the microphone way or conversation beside it have been avoided.

7. Acoustic and electric calibrations are done according to the guidelines

\section{Calibration}

In order to ensure the accuracy in measuring by the sound level meter it is necessary to calibrate it with a standard audio generator. The sound level meter uses a calibration factor to correct the errors. So that a signal with a specific sound intensity and frequency which is propagated by an accepted calibrator is compared with a signal that the audio signal level meter has red. The calibration level that the device shows is dependent on how the microphone responses that can be adjusted in the preparation stage of the device.

For calibration, first the microphone is inserted into the calibrator, and then Calibrator and sound level meter are placed into a horizontal plane. After turning on the device first the initial message is displayed and finally the calibration screen appears. This state of the monitor shows the current level of sound and details of the last calibration. The calibrator is turned on and in the monitor screen the value of the measured sound through the device is red. If the sound level displayed based on the type of microphone and the response ne not appropriate, automatic correction will be done.

For device calibration, CEL-110/2 calibration is used and the calibration operation is done by the company representative in Iran.

\section{Determination of Measurement Stations}

Due to the extent of Imam Khomeini International airport and the existence of different buildings and centers, including police sites, protection, revolutionary guard corps, executor of plan, substations, residential complex, administration building, customs, passport office, control tower and passenger terminal and many other ancillary buildings, to select the measurement stations at the ground part of the airport, places that seems to have a greater share in airport noise pollution, were selected.

But in this selection, indoor pollution such as inside the passenger terminal, customs and cargo warehouses are ignored and only outdoor audio polluting centers take into consideration. Thus, measurement stations are limited to the apron and runway, safe site on the ground (which is a set of flying field factors, firefighting, and risk and rescue), Dock (as a place for loading and unloading of passengers' baggage and the traffic load trolley), water refinery, the watchtower, taxi parking and pilgrims 'terminal.

\section{Measurement of the pollution and analysis of the data}

Typically, environmental noise measurement stations are placed at the very end side of the target area and onany side a sound station is monitored. The exact location of measurement stations has been done based on sound sources, distance, duration and continuity of sound around the site.

In order to compare and evaluate the designated station pollution, the proposed standard of environmental protection agency which is presented about the noise level in open-air areas in table 2 has been used.

Table 2. The audio Standard in the open air in Iran (Environmental Protection Agency) (Araghi \& Yaghobi, 2015)

\begin{tabular}{ll}
\hline Area type & Day (7 am to 22 pm)Night (7 am to 22 pm) \\
\hline Residential area & $55 \mathrm{~dB}$ \\
\hline
\end{tabular}




\begin{tabular}{lrr} 
Residential and commercial area60 dB & $50 \mathrm{~dB}$ \\
Commercial area & $65 \mathrm{~dB}$ & $55 \mathrm{~dB}$ \\
Residential - Industrial area & $70 \mathrm{~dB}$ & $60 \mathrm{~dB}$ \\
Industrial area & $75 \mathrm{~dB}$ & $65 \mathrm{~dB}$ \\
\hline
\end{tabular}

Based on the selected places, measurement was conducted in fifteen station and all the data and measurements are presented in table 3 for and integrated view and comparison.

Table 3. Sound measurement at selected sampling locations

\begin{tabular}{|c|c|c|c|c|c|c|}
\hline \multirow{2}{*}{\multicolumn{2}{|c|}{ RowSampling position }} & \multirow[t]{3}{*}{ Location } & \multirow{2}{*}{\multicolumn{4}{|c|}{$\begin{array}{l}\begin{array}{l}\text { Sound Leq } 30-\mathrm{dB} \text { Sound Leq } 30-\mathrm{dB} \\
\text { (Night) }\end{array} \\
\text { (Day) }\end{array}$}} \\
\hline & & & & & & \\
\hline & & & \multirow[t]{2}{*}{ Max } & \multirow[t]{2}{*}{ Min Leq30 } & Max & \multirow{2}{*}{$\begin{array}{l}\text { Min Leq30 } \\
69.873 .3\end{array}$} \\
\hline 1 & Apron-Left 112 & $\begin{array}{l}\text { AIR BUS 300-600-Mahan } \\
\text { (Drop off passengers) }\end{array}$ & & & 81.2 & \\
\hline 2 & Apron-Left 113 & $\begin{array}{l}\text { AIR BUS 300-600-Iran air } \\
\text { (When parking) }\end{array}$ & 99.7 & 78.396 .1 & & \\
\hline 3 & Runway & $\begin{array}{l}\text { EMBRARER 199-Oman Air } \\
\text { (Takeoff) }\end{array}$ & & & 92.3 & 69.481 .8 \\
\hline 4 & $\begin{array}{l}\text { StandD1-110 } \\
\text { (Aircraft parking ar }\end{array}$ & \multicolumn{3}{|c|}{$\begin{array}{l}\text { AIR BUS A340-600-Lufthansa114.2 90.7 108.4 } \\
\text { g)(When parking) }\end{array}$} & & \\
\hline 5 & Dock & North side & 83.8 & 63.166 .4 & & \\
\hline 6 & Dock & South side & 67.9 & 65.471 .3 & & \\
\hline 7 & Dock & East side & 75.2 & 66.974 .2 & & \\
\hline 8 & Dock & West side & 89.1 & 62.578 .2 & & \\
\hline 9 & Ground Safety & When the machines are on & & & 83.4 & 78.578 .9 \\
\hline & Ground Safety & Sirens - sirens front & & & 114.6 & 56.8107 .2 \\
\hline & Ground Safety & Station area & & & 100. & 58.496 .7 \\
\hline & Water refinery & North side & & & 64.4 & 61.562 .3 \\
\hline 13 & Watchtower & South side & & & 63.1 & 55.755 \\
\hline 14 & Taxi parking & East side & & & 67.1 & 59.164 .8 \\
\hline & Pilgrims terminals & West side & & & .1 & $45 \quad 48.9$ \\
\hline \multicolumn{2}{|c|}{ Environmental standard } & & 60 & & 70 & \\
\hline
\end{tabular}

Based on environmental standards of table 2 and according to airport operating conditions, for residential Industrial area the values of $70 \mathrm{~dB}$ for measuring time of day and $60 \mathrm{~dB}$ at night were selected as the allowed limits.

According to table 3, we see that the equivalent sound pressure levels at apron and runway, ground safety and dock exceeds the environmental standards of Iran and causing severe noise in the airport area which causes severe harassment of the residents,particularly flight personnelwhich are deployed on the runway such as safety of ground personnel, porters and other staff.

Figure 1 shows the result of environmental sound measurement for fifteen stations and the compare with environmental standards based on the equivalent sound pressure levels in both night and day. 


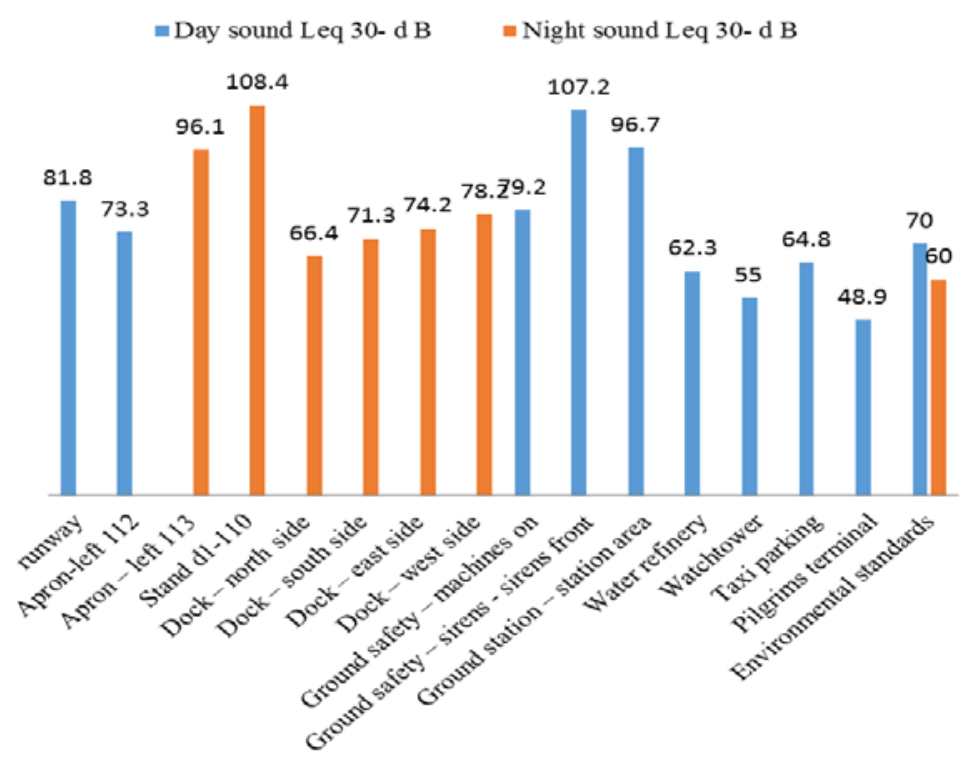

Figure 1. Comparative chart of the environmental noise results at the measured stations

In the figures 2 to 5 the pollution of each of the apron and runway, dock, ground safety and peripheral sites are compared separately with the allowed values of the Iran environmental standards.

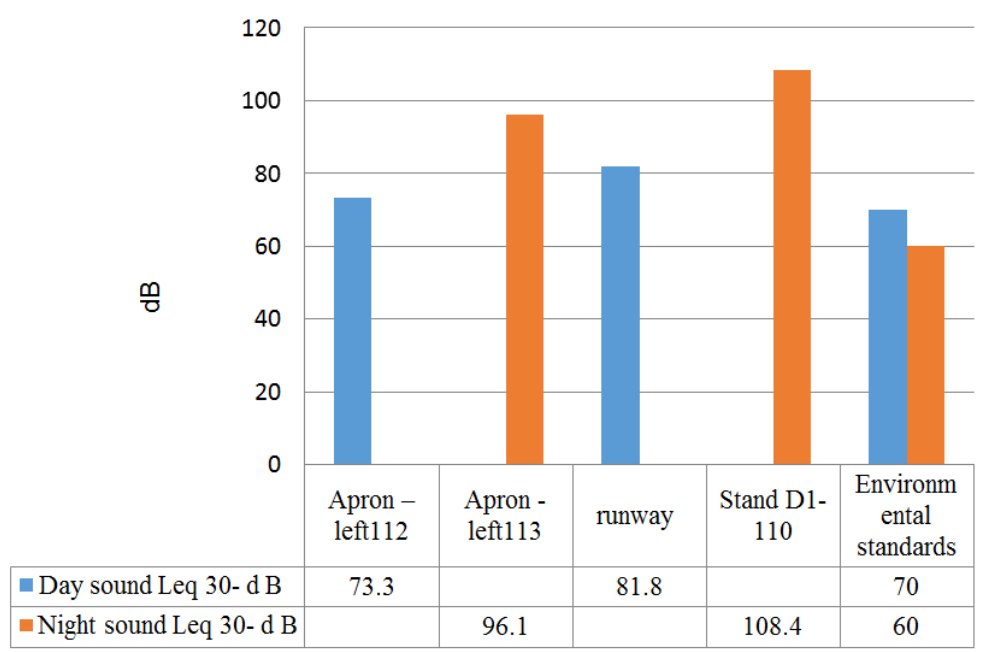

Figure 2. Comparative chart of apron and runway environmental noise results

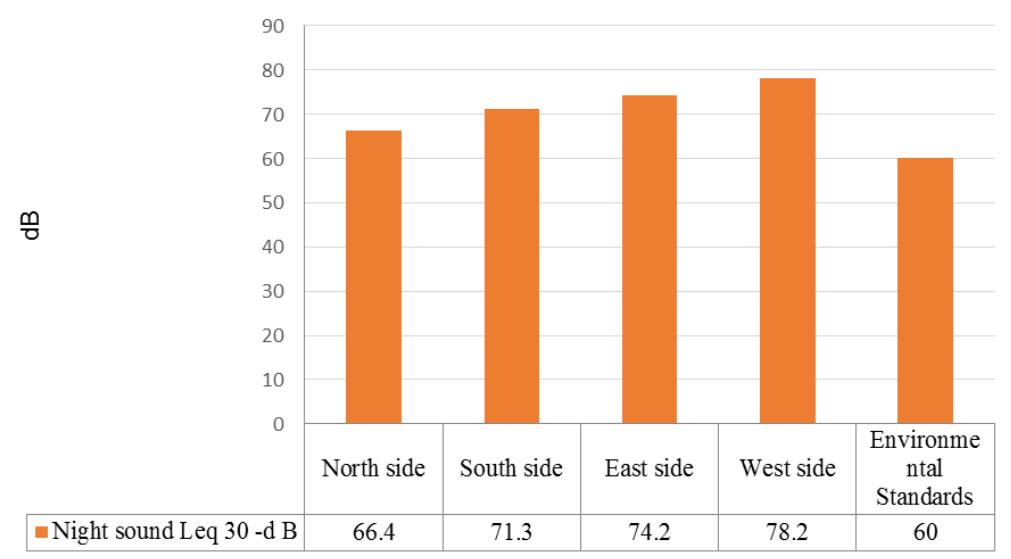

Figure 3. Comparative chart of environmental noise results of the dock site 


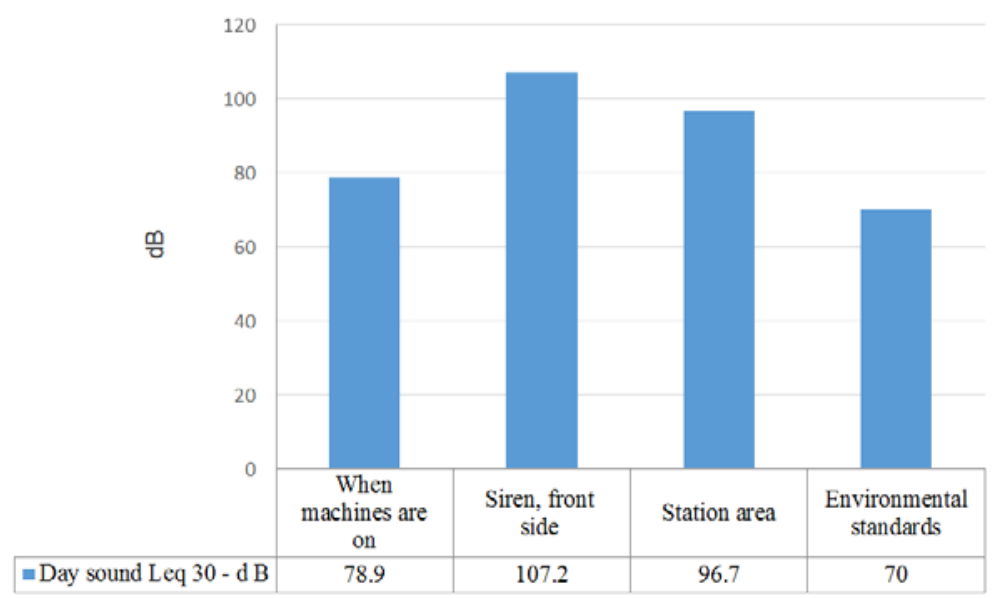

Figure 4. Comparative chart of environmental noise results of the ground safety

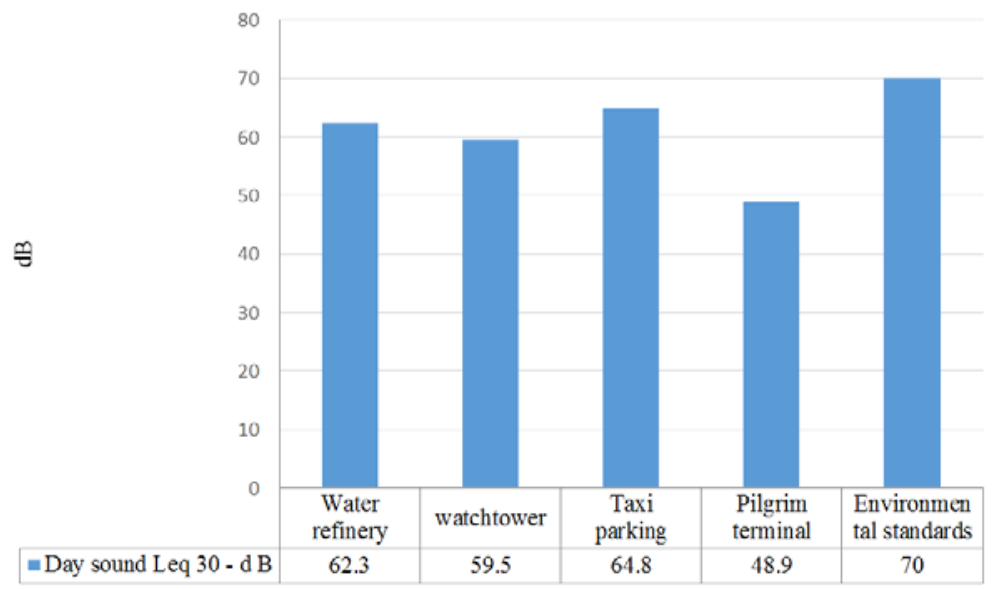

Figure 5. Comparative chart of environmental noise results ofaccessories sites

In order to categorize and obtaining results from the above figures and tables, the diversion of each of the fifteen stations measured from the Iran allowable environmental standard is summarized in figure 4.

Table 4. Noise pollution deviation from the environmental standards

\begin{tabular}{|c|c|c|c|c|c|c|c|c|c|}
\hline $\begin{array}{l}3 \\
0 \\
2 \\
\end{array}$ & 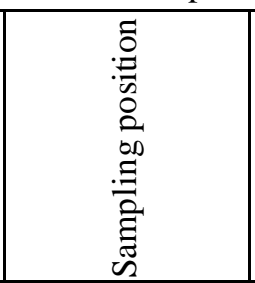 & 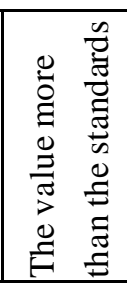 & 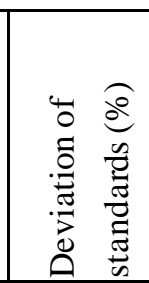 & 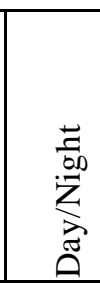 & 3 & 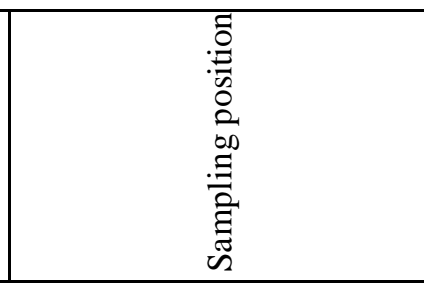 & 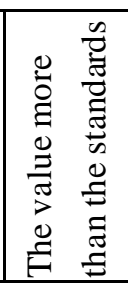 & 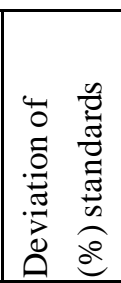 & 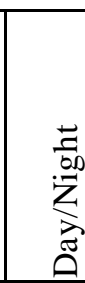 \\
\hline 1 & Apron- Left 112 & 3.3 & 4.7 & Day & 9 & $\begin{array}{l}\text { Ground safety - when the } \\
\text { machines are on }\end{array}$ & 8.9 & 12.7 & Day \\
\hline 2 & Apron- Left 113 & 36.1 & 60.2 & Night & 10 & $\begin{array}{l}\text { Ground safety -sirens - sirens } \\
\text { front }\end{array}$ & 37.2 & 53.1 & Day \\
\hline$\overline{3}$ & Runway & 11.4 & 16.3 & Day & 11 & Ground safety - station area & 26.7 & 38.1 & Day \\
\hline 4 & StandD1 - 110 & 48.4 & 80.7 & Night & 12 & Water refinery-north side & Allowed & -- & Day \\
\hline 5 & Dock- North side & 6.4 & 10.7 & Night & 13 & Watchtower - south side & Allowed & --- & Day \\
\hline 6 & Dock- south side & 11.3 & 18.8 & Night & 14 & Taxi parking - east side & Allowed & -- & Day \\
\hline 7 & Dock- east side & 14.2 & 23.7 & Night & 15 & Pilgrim terminal - west side & Allowed & -- & Day \\
\hline 8 II & Dock- west side & 18.2 & 30.3 & Night & & & & & \\
\hline
\end{tabular}




\section{Conclusion}

1. Based on the measurements of Equivalent Sound Level (Leq) from fifteen station and comparison with environmental standard values, apron and runway centers, ground safety and dock were identified as the most polluting sources of noise.

2. The noise of stations and water refinery sites, the watchtower, the taxi parking and pilgrims' terminal was lower than the standard values and noise pollution is not remarkable.

3. Most noise pollution is related to the apron and runway areas with 80.7 percent more than the allowed limit at night, which this noise is risky for the staff health, especially those who through their duty are exposed to intense noise of airplanes.

4. The highest noise during playback ground safety siren is $53.1 \%$ more than the standard limit at the day, and at night this is $61.6 \%$.

5. The average deviation of sound pollution for the dock is $20.88 \%$ more than the standard limit at night, and this value is 15.5 at day.

According to the results of measuring sound levels in the study area, the adverse impact of high levels of noise on employees, persons and adjacent areas is obvious. Therefore, implementing rigorous rules for the mandatory use of personal protective equipment such as ear plugs, listen stuck and helmet which is the most effective hearing protection devices, should be applied as the deterrent of noise pollution.

Also, the following strategies can be mentioned to deal with noise:

1. Shortening the working time of the employees to shifts of 12 hours work, 24 hours of rest and 24 hours work, 48 hours of rest is necessary.

2. It is recommended that to reduce and control the sound in the direction of sound propagation insulation tape on the floor like SBR layer which based on Iranian National Standard No. 2-8834 is able to reduce the noise level of Percussion sound as much as $14 \mathrm{~dB}$ be used.

3. To reduce and control the soundIn the direction of sound propagation the color of sound insulation ND, Anti Sound which is designed to prevent and reduce noise and according the TS 140-4 standard in the Turkkak laboratory one layer with the thickness of $1 \mathrm{~mm}$ can reduce the noise up to $51.2 \mathrm{~dB}$ at a frequency of 1000 $\mathrm{Hz}$ and absorb it, can be used.

4. In the ground safety of the open field, removing the existing garden in the east and west of the site and planting of Tehran-type cypress trees which are resistant to the drought, heat and cold and can tolerate the temperatures of 65 and $-26{ }^{\circ} \mathrm{C}$ along the north-south and at both sides of the safesite on the ground is recommended.

5. It is recommended in the selection of applicants for these jobs, from the audio logical point of view people with normal audiogram be selected and for a period of 6 months to one year depending on the severity of noise, undergo periodic examination.

\section{References}

Araghi, M., \& Yaghobi, M. (2015). The Study of Noise Pollution Caused by Birjand Airport on the Surrounding Residents. Indian Journal of Science and Technology, 8(11). https://doi.org/10.17485/ijst/2015/v8i11/71297.

Ezati, R., \& Atiekar, A. (2013). A study on the effects of urban noise pollution with an emphasis on traffic pollution on humans. in Persian, First International Conference and the National Conference on Environmental Protection and Planning.

Fan, Y. Z. (2011). Zhu Jun, Z. An Assessment of Psychological Noise Reduction by Landscape Plants. Int. J. Environ. Res. Public Health 2011, 8, 1032-1048; doi: 10.3390/ijerph8041032.

Fang, C., \& Ling, D. (2005). Guidance for noise reduction provided by tree belts. Landscape and Urban Planning $71,29.34$.

Fransses, E. A. (2014). Air craft noise around a large international airport and its inxpact on general health and edication use occupe Environ Med.

Geravi, A. (2012). The Role of aircraft noise pollution on the environment and international environmental laws and regulations and its modern control strategies. In Persian, Second National Conference on Environmental Protection Planning.

Hardoy, M. C. (2005). Exposure to aircraft noise and risk of psychiatric disorders: the Elmas survey-aircraft noise and psychiatric disorders. Socpsycliatry Epidemialjan.

Huddart, L. (1990). The use of vegetation for traffic noise screening. Crowthorne, erkshire: U. K. Transport and 
Road Research Laboratory Research Report, p.238.

Jeony, K. (2014). Exposure-Resporse Relationship Aircraft noise and sleep quality Aommunity-based cross-sectional study-osony public health perspect.

Khali, M., \& Frohideh, A. (2012). Environmental risk factors in Tehran City's two airport by the measurement of risk grading scoring. In Persian,Twelfth International Conference on Transportation and Traffic.

Mahir, G. M. (2012). Study of the road traffic noise in Erzurum-Turkey. Gekdag Iranian Journal of Environmental Health Sciences \& Engineering, 9, 22.

Maleki, K., et al. (2008). The importance of urban green space in reduces noise pollution. in Persian, National Conference on fuel, energy, environment.

Najafvand, S., Beyranvand, \& Heydari, K. (2015). Survey and Analysis of underground Concrete Structures Tunnel Doors, Under Explosive Loading,. Journal of Innovative Research in Engineering Sciences, 3(1)26-32.

Naseri, F., Irani, M., \& Dehkhodarajabi, M. (2016). Effect of graphene oxide nanosheets on the geotechnical properties of cemented silty soil. Archives of Civil and Mechanical Engineering, 16(4), 695-701.

Oveisi, Kh., et al. (2013). Noise pollution modeling of Mehrabad airport's twenty-year plan and determination of the land use around the airport. in Persian,First International Conference and Fourth National Conference on Urban.

Ravanshadnia, M. (2014). Safety management in construction projects. in Persian, Knowledge Broadcasting Institute Press.

Saffarzadeh, M., \& Rahimi, F. (2003). Noise pollution in transport systems. in Persian, EPA Press.

Shirazian, Gh., \& Frohideh, A. (2011). The effects of noise pollution in residential areas surrounding the airport. in persian Fifth National Conference and proffesional Exhibitions of Environmental Engineering.

Stamsfeld, A. \& Stephan (2003). Oxford Journals Medicine and health British Medical Bulletin,Volumes 80 issue $l$.

Yazdi, M., et al. (2012). Measuring and monitoring noise pollution caused by Yazd airport and provide management strategies to mitigate it. in Persian, The first national conference on strategies to achieve sustainable development.

Zabihi Tary, M., et al. (2011). Determine the desired level of activity of Mehrabad airport using noise pollution analysis with NEF software modeling. in Persian, Eleventh International Conference on Transportation and Traffic Engineering.

\section{Copyrights}

Copyright for this article is retained by the author(s), with first publication rights granted to the journal.

This is an open-access article distributed under the terms and conditions of the Creative Commons Attribution license (http://creativecommons.org/licenses/by/4.0/). 